\title{
Utility of Global Longitudinal Strain to Predict Post-Operative Outcomes in Non-Cardiac Surgeries
}

\author{
Chang Joon Park', Liy Si Tan ${ }^{2}$, Pei Huang ${ }^{2}$, Puay Joo Tan'², Jason Jia Hao See, MBBS, MRCP ${ }^{*}$ \\ ${ }^{1}$ Yong Loo Lin School of Medicine, National University of Singapore, Singapore \\ ${ }^{2}$ Clinical Measurement Unit, Changi General Hospital, Singapore \\ ${ }^{3}$ Department of Cardiology, Changi General Hospital, Singapore

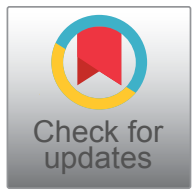

*Corresponding author: Jason Jia Hao See, MBBS, MRCP, Department of Cardiology, Changi General Hospital, 2 Simei Street 3, 529889, Singapore, Tel: 65-6788-8833

\begin{abstract}
Background: Pre-operative echocardiography is performed in select groups of patients for cardiac risk stratification. Many parameters, including Left Ventricular Ejection Fraction (LVEF), are assessed during echocardiography. While many studies have cited association between low LVEF and poor operative outcomes, patients with preserved LVEF might have subtle LV dysfunction that may result in adverse outcome. Studies have described the routine use of global longitudinal strain (GLS) as an alternative measure of ventricular function that can detect subtle LV dysfunction. The aim of this study is to determine the value of GLS in predicting post-operative outcomes in non-cardiac surgeries.

Methods: This was a retrospective study of patients who had normal LVEF, had undergone subsequent non-cardiac surgery, and had post-operative troponins measured. Outcomes for post-operative myocardial injury, as well as hospital re-admissions and mortality up to 1-year post-surgery were collected. Post-op myocardial injury was defined as a peak Troponin $\mathrm{T}$ value of $>0.030 \mathrm{ng} / \mathrm{dL}$ or a $>20 \%$ increment from baseline.
\end{abstract}

Results: A total of 42 patients were included. $61.9 \%$ ( $n=$ 26 ) were males and mean age was 72.3 years. Mortality at 1 year was $14.3 \%(n=6)$ and $28.6 \%(n=12)$ were deemed to have post-operative myocardial injury. 1-year mortality was associated with lower GLS $(-18.95 \%$ vs. $-23.75 \%, p=$ $0.001)$. However, GLS was not associated with post-operative myocardial injury and hospital readmissions.

Conclusion: Although GLS values were decreased in non-survivors, our study did not demonstrate the utility of GLS in predicting post-operative events.

\section{Introduction}

Post-operative adverse events in non-cardiac surgery are an important cause of morbidity and mortality. Pre-operative assessment aims to evaluate such risks so that measures can be implemented to prepare higher risk patients for surgery. Transthoracic echocardiography is a safe, non-invasive and reproducible technique and its use is becoming increasingly popular in the pre-operative assessment of patients with, or who are at risk of cardiovascular disease. Guidelines include indications for resting echocardiography in selected patients, for example those with heart failure or valvular heart disease $[1,2]$. However, even unselected patients have been shown to have a substantial risk of perioperative cardiac events $[3,4]$, and resting echocardiography could have a role in the identification of these patients.

During echocardiography, many parameters, including Left Ventricular Ejection Fraction (LVEF), are assessed. While studies have cited association between low LVEF and poor operative outcomes such as mortality and perioperative myocardial infarction [5], the usage of LVEF assessment has limitations as patients with preserved LVEF could have subtle or subclinical left ventricular (LV) dysfunction. Studies have described the routine use of global longitudinal strain (GLS) as an alternative measure of ventricular function, with GLS having been reported to be a reliable marker in detecting subclinical LV dysfunction $[6,7]$. Other than the

Citation: Park CJ, Tan LS, Huang P, Tan PJ, See JJH (2021) Utility of Global Longitudinal Strain to Predict Post-Operative Outcomes in Non-Cardiac Surgeries. Int J Clin Cardiol 8:217. doi.org/10.23937/23782951/1410217

Accepted: February 11, 2021: Published: February 13, 2021

Copyright: (C) 2021 Park CJ, et al. This is an open-access article distributed under the terms of the Creative Commons Attribution License, which permits unrestricted use, distribution, and reproduction in any medium, provided the original author and source are credited. 
potential to improve cardiovascular risk stratification in subjects with normal LVEF, GLS has also shown good reproducibility [8]. This adds incremental value in predicting myocardial function and in risk stratification. In fact, several studies have documented GLS being a useful preoperative parameter in predicting postoperative LV dysfunction and adverse events after cardiac valve surgery.

The aim of our study is to determine the value of GLS in predicting post-procedural outcomes in patients with normal LVEF undergoing non-cardiac surgeries.

\section{Methods}

This was a retrospective study of all patients who had echocardiography performed for a pre-operative indication from February 2017 to October 2017. These patients were screened for those who had normal LVEF, had undergone subsequent non-cardiac surgery, and had post-operative troponins measured. Medical records were traced for baseline demographics, past medical history and echocardiographic parameters (including measures of diastology such as E/A ratio, E/e', indexed left atrium size and maximal tricuspid regurgitation velocity). GLS evaluation of pre-operative echocardiographic data was performed using TOMTEC-ARENA TTA2 (TOMTEC Imaging Systems $\mathrm{GmbH}$ ) by assessors blinded to patient outcomes. Outcomes for post-operative myocardial injury, as well as hospital re-admissions and mortality up to 1 year post-surgery were collected. Post-op myocardial injury was defined as a peak Troponin T value of $>0.030$ $\mathrm{ng} / \mathrm{dL}$ (which is above the $99^{\text {th }}$ percentile upper reference limit for our laboratory) and/or a troponin level with > $20 \%$ increment from baseline within the same admission [9]. Statistical analysis was performed using IBM SPSS Statistics 19.0 (IBM Corp, Armonk, NY, USA). Data was expressed as mean \pm standard deviation for continuous variables, and percentages or numbers for categorical variables. Categorical and dichotomous variables were compared using chi-square test or Fisher's exact test (in cases where number of observations were less than five). Continuous variables were compared with $t$-test.

Ethics approval for this project was obtained from the local Centralised Institutional Review Board.

\section{Results}

A total of 42 patients were included. $61.9 \%(n=26)$ were males and mean age was 72.3 years. A significant number of them had comorbidities including diabetes, ischaemic heart disease and chronic kidney disease (Table 1). Orthopaedic surgery was found to be the commonest type of surgery performed (Table 2).

Mortality at 1 year was $14.3 \%(n=6)$ and $28.6 \%(n$ $=12$ ) were deemed to have post-operative myocardial injury. 1-year mortality was associated with a lower GLS $(-18.95 \% \pm 1.57 \%$ vs. $-23.75 \% \pm 3.21 \%, p=0.001)$. However, GLS was not associated with other post-ope-
Table 1: Prevalence of comorbidities, $\mathrm{n}(\%)$.

\begin{tabular}{|l|l|}
\hline Diabetes & $23(54.8 \%)$ \\
\hline Hyperlipidemia & $30(71.4 \%)$ \\
\hline Hypertension & $34(81.0 \%)$ \\
\hline Atrial fibrillation & $6(14.3 \%)$ \\
\hline History of congestive cardiac failure & $5(11.9 \%)$ \\
\hline History of ischaemic heart disease & $12(28.6 \%)$ \\
\hline Chronic kidney disease & $12(28.6 \%)$ \\
\hline History of stroke/transient ischemic attack & $7(16.7 \%)$ \\
\hline Active cancer & $11(26.2 \%)$ \\
\hline
\end{tabular}

Table 2: Types of procedures, $n$ (\%).

\begin{tabular}{|l|l|}
\hline General & $4(9.5 \%)$ \\
\hline Colorectal & $2(4.8 \%)$ \\
\hline Hepatobiliary & $6(14.3 \%)$ \\
\hline Vascular & $6(14.3 \%)$ \\
\hline Urology & $4(9.5 \%)$ \\
\hline Orthopaedics & $15(35.7 \%)$ \\
\hline Endoscopy & $5(11.9 \%)$ \\
\hline
\end{tabular}

rative events such as post-operative myocardial injury and hospital readmissions. In our study population, only a history of ischemic heart disease predicted post-operative myocardial injury (58.3\% vs. $16.7 \%, p=0.019)$ (Table 3).

Other demographic or echocardiographic factors were also not associated with significant differences in outcomes except a history of active cancer that was associated with 1-year mortality ( $66.7 \%$ vs. $19.4 \%, p=$ 0.032). There was, however, no significant difference in GLS between those with and without active cancer $(-22.35 \pm 3.43$ vs. $-23.31 \pm 3.49, p=0.435)$.

\section{Discussion}

Global longitudinal strain is an echocardiographic marker that can be useful in the pre-operative evaluation of patients undergoing surgery. While multiple studies have provided support with regards to the additional prognostic value that GLS adds in preoperative management, majority were in populations undergoing cardiac surgeries [10-12]. Our study aimed to evaluate the utility of GLS in the assessment of patients with normal LVEF undergoing non-cardiac surgeries.

Our study population had a relatively high rate of post-operative myocardial injury. This could be attributed to our study population having multiple cardiovascular risk factors. More than half of them had either diabetes, hyperlipidemia, or hypertension and more than a quarter had a history of ischemic heart disease. Unsurprisingly, a statistically significant association between a history of ischaemic heart disease and post-operative myocardial injury was found. Although GLS was not associated with post-operative myocardial injury, our result could have been limited by our small sample size. 


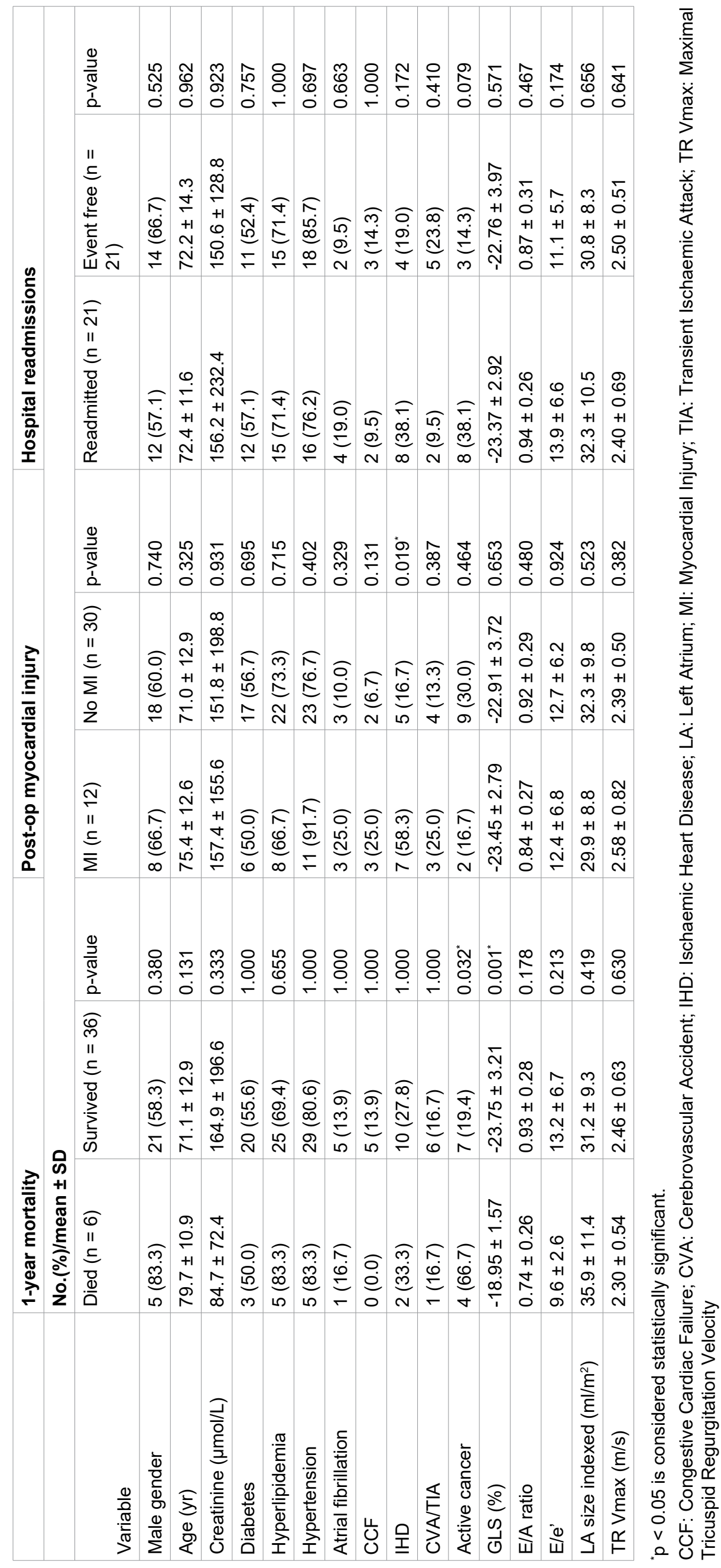


It is also worth noting that our study showed lower GLS having an association with increased 1-year mortality. A study by Dahl, et al. showed that there was an association between lower GLS values and cardiac mortality in patients undergoing aortic valve replacement [13], raising the possibility that GLS has prognostic value involving a mechanism where myocardial structure is affected and thus contributing to a worsening cardiac function thereafter. This is further demonstrated by Wiedemann, et al. where an association between myocardial fibrosis and low GLS suggested that the structure of the heart that gives rise to its function may be affected in severe aortic stenosis [14]. In our study population, we postulate that lower GLS are a reflection of underlying myocardial structural changes and subclinical dysfunction that lead to increased mortality.

Our study had a number of limitations. The first is our small sample size as mentioned above, limiting our study's ability to detect differences. Indeed, GLS was not shown to predict other outcomes such as myocardial injury and hospital readmissions. Furthermore, traditional cardiac risk factors [4], such as congestive cardiac failure and cerebrovascular disease, were numerically different when comparing the rates of post-operative myocardial injury but were not shown to be statistically significant in our study. Secondly, there was a wide spectrum of various surgeries being performed under differing anaesthetic methods. There are differences of each; where emergency surgeries tend to have higher mortality compared to elective ones $[15,16]$ and general anaesthesia being associated with more post-operative complications and cardiac events $[17,18]$. Presence of such differences can have a significant impact in determining outcomes but these were not specifically looked at in our study. Lastly, our sample selection could have been biased as the selected patients who had troponins performed could have been sicker to begin with or had other clinical indications for the cardiac troponins to be measured, and this could have contributed to the relatively high post-operative rates of myocardial injury.

In conclusion, GLS is an echocardiographic parameter that has potential for use in the pre-operative setting due to its ability to detect subclinical LV dysfunction. Current literature suggests its usefulness as a prognostic marker for post-operative events in patients undergoing cardiac surgeries. Although our small study sample did not demonstrate the utility of GLS in predicting post-operative events, GLS values were lower in non-survivors and further study should be done to evaluate the utility of GLS in the pre-operative setting.

\section{Authors Declaration}

No potential conflict of interest relevant to this article was reported.

IRB: 2018/3003 (Singapore Health Services Centralised Institutional Review Board)
Clinical trial registration number: Not applicable.

\section{References}

1. Douglas PS, Garcia MJ, Haines DE, Lai WW, Manning WJ, et al. (2011) ACCF/ASE/AHA/ASNC/HFSA/HRS/SCAI/ SCCM/SCCT/SCMR 2011 appropriate use criteria for echocardiography. J Am Soc Echocardiogr 24: 229-267.

2. Fleisher LA, Fleischmann KE, Auerbach AD, Barnason SA, Beckman JA, et al. (2014) 2014 ACC/AHA guideline on perioperative cardiovascular evaluation and management of patients undergoing noncardiac surgery: Executive summary: A report of the American College of Cardiology/American Heart Association Task Force on Practice Guidelines. Circulation 130: 2215-2245.

3. Mangano DT (1998) Adverse outcomes after surgery in the year 2001 -- a continuing odyssey. Anesthesiology 88: 561564.

4. Lee TH, Marcantonio ER, Mangione CM, Thomas EJ, Polanczyk CA, et al. (1999) Derivation and prospective validation of a simple index for prediction of cardiac risk of major noncardiac surgery. Circulation 100: 1043-1049.

5. Pieri M, Belletti A, Monaco F, Pisano A, Musu M, et al. (2016) Outcome of cardiac surgery in patients with low preoperative ejection fraction. BMC Anesthesiol 16: 97.

6. Reisner SA, Lysyansky P, Agmon Y, Mutlak D, Lessick J, et al. (2004) Global longitudinal strain: A novel index of left ventricular systolic function. J Am Soc Echocardiogr 17: 630-633.

7. Russo C, Jin Z, Elkind MSV, Rundek T, Homma S, et al. (2014) Prevalence and prognostic value of subclinical left ventricular systolic dysfunction by global longitudinal strain in a community-based cohort. Eur J Heart Fail 16: 13011309.

8. Risum N, Ali S, Olsen NT, Jons C, Khouri MG, et al. (2012) Variability of global left ventricular deformation analysis using vendor dependent and independent two-dimensional speckle-tracking software in adults. J Am Soc Echocardiogr 25: 1195-1203.

9. Thygesen K, Alpert JS, Jaffe AS, Chaitman BR, Bax JJ, et al. (2019) Fourth universal definition of myocardial infarction (2018). European Heart Journal 40: 237-269.

10. Mascle S, Schnell F, Thebault C, Corbineau H, Laurent M, et al. (2012) Predictive value of global longitudinal strain in a surgical population of organic mitral regurgitation. J Am Soc Echocardiogr 25: 766-772.

11. Witkowski TG, Thomas JD, Debonnaire PJ, Delgado V, Hoke U, et al. (2013) Global longitudinal strain predicts left ventricular dysfunction after mitral valve repair. Eur Heart J Cardiovasc Imaging 14: 69-76.

12. Ternacle J, Berry M, Alonso E, Kloeckner M, Couetil JP, et al. (2012) Incremental value of global longitudinal strain for predicting early outcome after cardiac surgery. Eur Heart $\mathrm{J}$ Cardiovasc Imaging 14: 77-84.

13. Dahl JS, Videbæk L, Poulsen MK, Rudbæk TR, Pellikka PA, et al. (2012) Global strain in severe aortic valve stenosis: Relation to clinical outcome after aortic valve replacement. Circ Cardiovasc Imaging 5: 613-620.

14. Weidemann F, Herrmann S, Störk S, Niemann M, Frantz S, et al. (2009) Impact of myocardial fibrosis in patients with symptomatic severe aortic stenosis. Circulation 120: 577 584.

15. Havens JM, Peetz AB, Do WS, Cooper Z, Kelly E, et al. 
(2015) The excess morbidity and mortality of emergency general surgery. J Trauma Acute Care Surg 78: 306-311.

16. Tottrup A, Erichsen R, Sværke C, Laurberg S, Srensen HT (2012) Thirty-day mortality after elective and emergency total colectomy in Danish patients with inflammatory bowe disease: A population-based nationwide cohort study. BMJ Open 2: e000823.
17. Bakker EJ, van de Luijtgaarden KM, van Lier F, Valentijn TM, Hoeks SE, et al. (2012) General anaesthesia is associated with adverse cardiac outcome after endovascular aneurysm repair. Eur J Vasc Endovasc Surg 44: 121-125.

18. Fields AC, Dieterich JD, Buterbaugh K, Moucha CS (2015) Short-term complications in hip fracture surgery using spinal versus general anaesthesia. Injury 46: 719-723. 